\title{
Optimization of
}

\section{6,13Bis(triisopropylsilylethynyl)pentacene (TIPS-Pentacene) Organic Field Effect Transistor: Annealing Temperature and Solvent Effects}

\author{
Diallo Abdoul Kadri'1, Diallo Abdou Karim², Mané Seck², Kobor Diouma1, Pasquinelli Marcel³ \\ ${ }^{1}$ Laboratoire de Chimie et de Physique des Matériaux (LCPM), Assane Seck University, Ziguinchor, Senegal \\ ${ }^{2}$ Gaston Berger University, Department of Applied Physics, Saint Louis, Senegal \\ ${ }^{3}$ OPTO-PV Group/Institut Matériaux Microélectronique Nanosciences de Provence (IM2NP), Marseille, France \\ Email: a.diallo3014@zig.univ.sn, abdou-karim.diallo@ugb.edu.sn
}

How to cite this paper: Kadri, D.A., Karim, D.A., Seck, M., Diouma, K. and Marcel, P. (2018) Optimization of 6,13Bis(triisopropylsilylethynyl)pentacene (TIPS-Pentacene) Organic Field Effect Transistor: Annealing Temperature andSolvent Effects. Materials Sciences and Applications, 9, 900-912. https://doi.org/10.4236/msa.2018.911065

Received: August 28, 2018

Accepted: October 27, 2018

Published: October 30, 2018

Copyright $\odot 2018$ by authors and Scientific Research Publishing Inc. This work is licensed under the Creative Commons Attribution International License (CC BY 4.0).

http://creativecommons.org/licenses/by/4.0/

\begin{abstract}
Abstract: In this contribution, we report on the effect of solvents with different boiling points and annealing temperature on the performance of TIPS-pentacene transistors. Several solvents have been used for TIPS-pentacene thin film processing: toluene, chlorobenzene and tetrahydrofuran. To study the influence of solvent and temperature; the electrical parameters of TIPS-pentacene field effect transistor were measured. The highest values of mobilities were $7.1 \times 10^{-3} \mathrm{~cm}^{2} \cdot \mathrm{V}^{-1} \cdot \mathrm{s}^{-1}, 4.5 \times 10^{-3} \mathrm{~cm}^{2} \cdot \mathrm{V}^{-1} \cdot \mathrm{s}^{-1}$ and $1.43 \times 10^{-3}$ $\mathrm{cm}^{2} \cdot \mathrm{V}^{-1} \cdot \mathrm{s}^{-1}$ respectively for TIPS-pentacene field effect transistor using chlorobenzene, toluene and tetrahydrofuran and annealed respectively at $120^{\circ} \mathrm{C}, 150^{\circ} \mathrm{C}$ and $120^{\circ} \mathrm{C}$. We have correlated these electrical performances with AFM images in order to point out the role of morphological properties. It is found that the grain size, and roughness highly affect the electrical parameters.
\end{abstract}

\section{Keywords}

Tips-Pentacene, Transistor, Solvent, Annealing Temperature

\section{Introduction}

Organic field-effect transistors (OFETs) have gained recently a lot of attraction in organic electronics. Since they achieve a good performance comparable to 
amorphous silicon (a-Si-H), organic transistors play a key role in next generation of electronic devices. Organic materials such as polymers and small molecules have potential advantages as active layers in the field-effect transistors (FETs) due to processable solution that allows them low-cost, large area and compatibility with flexible substrates [1] [2] [3]. Recently, many efforts have been done to making crystalline organic semiconducting thin films from solution for the use of organic field-effect transistor [4] [5]. Small molecule like 6,13-Bis(triisopropylsilyl)pentacene (TIPS-Pentacene) has gained a lot of consideration due to its environmental stability [6], its solubility in organic solvents [3] and its high field effect mobility higher than $1 \mathrm{~cm}^{2} \cdot \mathrm{V}^{-1} \cdot \mathrm{s}^{-1}$ [7] [8]. Solution-processed organic semiconductor active layers are highly interesting mostly in low-coast manufacturing approaches are needed. Hence several works have been done on TIPS-pentacene as active layer of electronics devices. Several studies were achieving to improve the performance of TIPS-pentacene organic field-effect transistors [8] [9] [10] [11] [12]. From those researches, one can identify the influence of process parameters in the performances of organic transistors. Even spin coating [13], dip coating [14] and Ink-jet printing [15] are currently the most widely used solution processing method in organic electronics, many other technics have been used to improve the crystalline film growth [8] [16]. Previous studies show that charge transport properties of organic semiconductor are widely dependent on their crystal structure and morphology [17]-[24]. In solution process, most of organic semiconductors require dissolution in organic solvent. Consequently, various works have done to explore the effect of annealing temperature [21] [25] [26] [27] [28] [29] and solvent influence on the thin film morphology and crystallinity [30]-[35]. It is well known that processing conditions impacted the electrical performances and especially when solvents and temperature are involved.

In this paper we study the influence of solvent and annealing temperature in TIPS-pentacene organic transistor. For that purpose three different solvents, chlorobenzene (CB), toluene and tetrahydrofuran (THF), have been used to dissolve the organic material. The temperature for post fabrication annealing was also chosen from non-annealing (as-prepared) to temperature above the boiling point of all solvents. In order to understand the electrical parameters change, we have correlated the electrical performances to thin film morphology by using atomic force microscopic (AFM) It turns out that the highest value of mobility was obtained with Toluene and chlorobenzene solvents at $\mathrm{T}=150^{\circ} \mathrm{C}$ and $120^{\circ} \mathrm{C}$ respectively.

\section{Experimental}

We used a prefabricated bottom-gate/bottom-contact (BG-BC) structure (as seen in Figure 1) from Fraunhofer IPMS. N-doped silicon (doping at wafer surface $\mathrm{n} \sim 3.10^{17} \mathrm{~cm}^{-3}$ ) are used as gate electrode with $230 \mathrm{~nm}$ of $\mathrm{SiO}_{2}$ (thermal oxidation) as dielectric. $30 \mathrm{~nm}$ Au with $10 \mathrm{~nm}$ high work function adhesion layer 


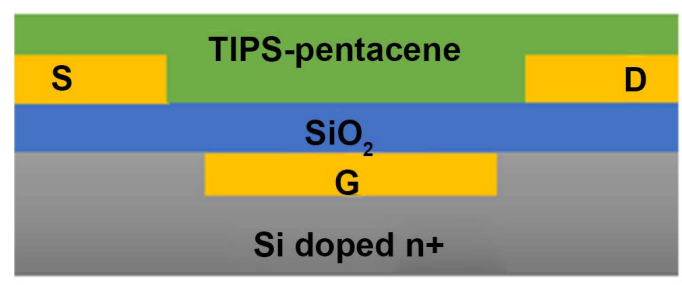

(a)

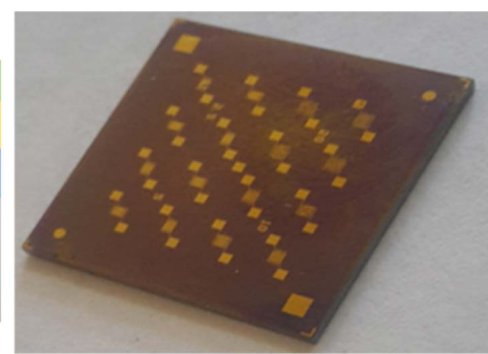

(b)

Figure 1. (a) schematic structure of Bottom gate-Bottom contact OFET and (b) image of BG-BC OFET.

(ITO) was deposited on wafer for source and drain contacts. All characterized OFETs present a channel length $(L)$ of $20 \mu \mathrm{m}$ and a width $(W)$ of $10 \mathrm{~mm}$. The devices fabrications begun by the classic steps of cleaning of substrates: sonication in detergent $(15 \mathrm{~min})$, acetone (15 $\mathrm{min}$ ) and isopropyl alcohol (15 $\mathrm{min}$ ) and deionized water. The substrates were then dried in a UV-Ozone for $15 \mathrm{~min}$ to remove organic residuals.

The organic material 6,13 bis(triisopropylsilylethynyl)-pentacene (TIPS-pentacene) was purchased from OSSILA. Three solutions for different solvents were prepared. $15 \mathrm{mg}$ of TIPS-pentacene was dissolved in $1 \mathrm{ml}$ of each solvent (CB, toluene and THF). Each solution was stirring for $24 \mathrm{~h}$ at $40^{\circ} \mathrm{C}$ to dissolve completely the organic material. The hexamethyldisilazane (HMDS) treatment is performed first to ensure a uniform adhesion of the film and solution dewetting on the substrate. $70 \mu \mathrm{l}$ of TIPS-pentacene solution is deposited on $\mathrm{Si} / \mathrm{SiO}_{2}$ substrate by spin coating to form thin film in two steps: the first one at $2000 \mathrm{rpm}$ for $120 \mathrm{~s}$ and the second one at ( $2500 \mathrm{rpm}$ for $60 \mathrm{~s}$ ). And then samples are annealed for $10 \mathrm{~min}$ before characterization. The chosen annealing temperature was $50^{\circ} \mathrm{C}$, $80^{\circ} \mathrm{C}, 100^{\circ} \mathrm{C}, 120^{\circ} \mathrm{C}$ and $150^{\circ} \mathrm{C}$, although we only showed the electrical characteristics of transistor devices for three different temperatures. The thickness of each TIPS-pentacene film was determined by a surface profiler BRUKER DektakXT. Optical proprieties are investigated by using a UV-visible spectrophotometer Perkin Elmer (150 mm InGaAs sphere). The morphology of thin film deposited on $\mathrm{SiO}_{2}$ was studied by using an XE-100 Atomic Force Microscopic (AFM)electrical characterization was performed by using KEITHLEY 4200-SCS semiconductor characterization system in a glovebox with controlled atmosphere.

The mobility $\mu$ was extracted from the saturation region of the transfer curves with the equation:

$$
I_{D, s a t}=\frac{W}{2 L} \mu C_{i}\left(V_{G}-V_{T h}\right)^{2}
$$

where $I_{D, s a t}$ is drain current in the saturation regime, $W / L$ is the width to length ratio, $C_{i}$ is the capacitance per unit area, $V_{G}$ the gate voltage and $V_{T h}$ the threshold voltage. 


\section{Results and Discussion}

\subsection{Effect of Solvent and Temperature on Optical Properties}

Optical experiment provides a good way to examine the properties of semiconductors. Measuring the absorption for various wavelength gives information about the band gap of the material, which is important for understanding the optical (electrical) properties of the semiconductors. Measurement are performed at room temperature on $60.5 \mathrm{~nm}, 88.56 \mathrm{~nm}$ and $250.0 \mathrm{~nm}$ of TIPS-pentacene film respectively from toluene, chlorobenzene (CB) and tetrahydrofuran (THF) as solvent.

Figures 2(a)-(c) show the absorption spectra of TIPS-pentacene thin film respectively for toluene, $\mathrm{CB}$ and THF as solvents.

The absorption curves shows that the absorption rate is higher in TIPS-pentacene thin film cast from tetrahydrofuran film (Figure 2(c)) than TIPS-pentacene film from toluene and chlorobenzene as solvent.

The absorptions spectra show intense peaks in redshift between $660 \mathrm{~nm}$ and $680 \mathrm{~nm}$. These peaks are attributed to electronic transition between the HOMO and the LUMO states and correspond to optical band gap wavelength [36]. From the Figure 2, there is no shift in the absorption spectra. It is just observed a small enhancement of the absorption rate in the case of toluene as solvent before and after thermal annealing. The increase in the absorption could be recognized as a better molecular organization in the annealed samples [28] which is confirmed by our AFM images of thin films from the three solvents.

Table 1 shows the optical band gap values of TIPS-pentacene for different annealing temperatures and for the three using solvents. By estimating the wavelength at the absorption edge in the absorption spectra, it is possible to calculate the optical band gap of TIPS-pentacene.

Optical band gap energy is obtained from the wavelength of the most intense peak by using Planck's equation:

$$
E_{g}=\frac{1240}{\lambda(n m)}
$$

where $\lambda$ correspond to the threshold absorption wavelength in the spectra and $E_{g}$ the optical band gap.

Vibronic bands in absorption spectra of TIPS-pentacene films show the influence of solvent, with relative intensities of the bands varied depending on the film thickness and the surface of the film. For example, films deposited with toluene as solvent, the absorption increase by increasing the annealing temperature, which correlates the absorption and the morphology. TIPS-pentacene films cast from toluene as solvent are better organized when the temperature increase. In contrast, the influence of temperature in THF as solvent in TIPS-pentacene thin films absorption is more visible compare to other solvents. Indeed one can see that the film's absorption increase as well as the temperature increases. These results suggest that the absorption depends only on film structure and 


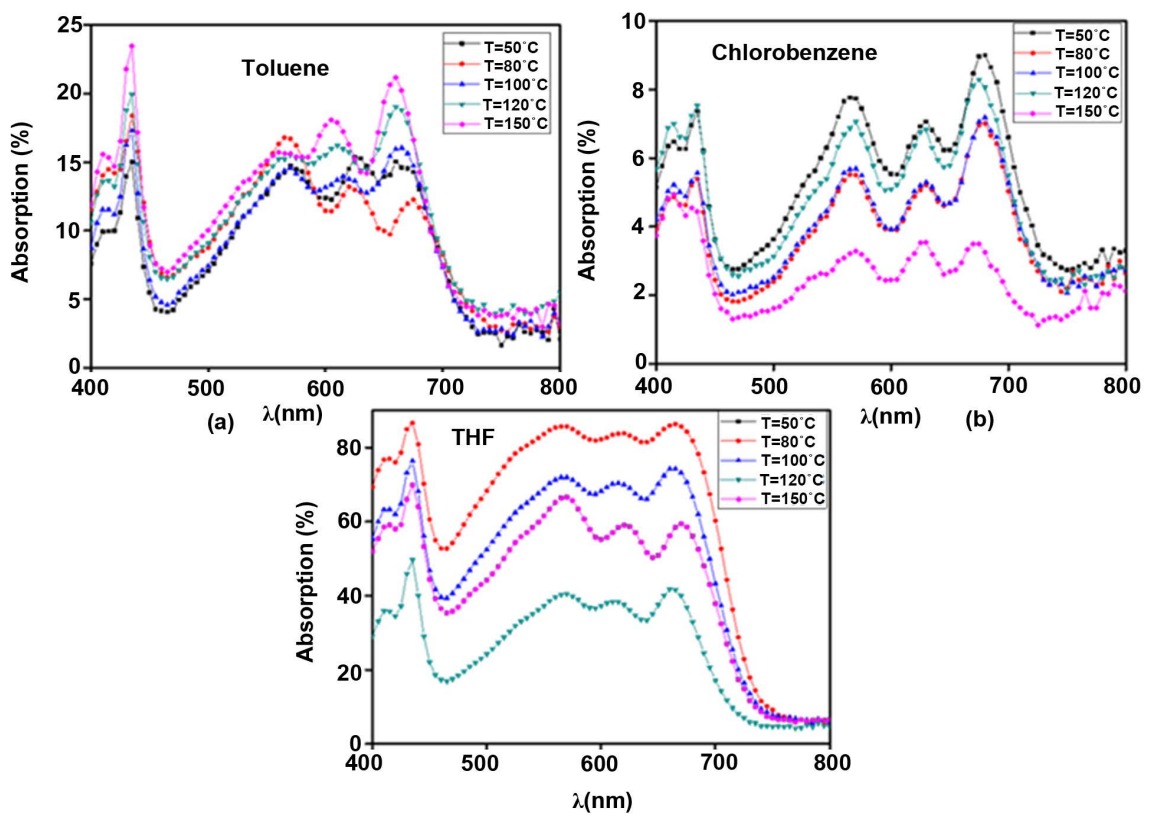

(c)

Figure 2. Absorption spectra of TIPS-pentacene film cast: (a) from toluene, (b) from Chlorobenzene (CB) and (c) from Tetrahydrofuran (THF).

Table 1. Optical band gap of TIPS-pentacene thin film obtained from different temperatures and solvent.

\begin{tabular}{cccc}
\hline Solvents & Toluene & $\mathrm{CB}$ & THF \\
\cline { 2 - 4 } $\mathrm{T}\left({ }^{\circ} \mathrm{C}\right)$ & $\mathrm{Eg}(\mathrm{eV})$ & $\mathrm{Eg}(\mathrm{eV})$ & $\mathrm{Eg}(\mathrm{eV})$ \\
\hline 50 & 1.68 & 1.69 & 1.67 \\
80 & 1.67 & 1.67 & 1.68 \\
100 & 1.69 & 1.70 & 1.67 \\
120 & 1.72 & 1.72 & 1.69 \\
150 & 1.68 & 1.72 & 1.67 \\
\hline
\end{tabular}

morphology in samples using toluene as solvent while in THF solvent, the annealing influence may be considered. This study shows that all values of the optical band gap are close to $1.6 \mathrm{eV}$ or $1.81 \mathrm{eV}$ [37] [38] [39] and less than that (1.91 $\mathrm{eV}$ ) given by Saeed et al. [40].

\subsection{Influence of Solvent and Annealing in Morphology and Electrical Performance}

The AFM results of the non-annealed and annealed samples have been investigated to obtain a better insight into the topographical changes as a result of the thermal annealing treatment and solvent effect. The AFM images of the TIPS-pentacene thin film deposited by toluene, chlorobenzene and tetrahydrofuran are respectively shown in Figure 3. It shows $1 \mu \mathrm{m} \times 1 \mu \mathrm{m}$ AFM topographic images of the TIPS-pentacene thin films before and after post fabrication thermal annealing at $120^{\circ} \mathrm{C}$ and $150^{\circ} \mathrm{C}$. 

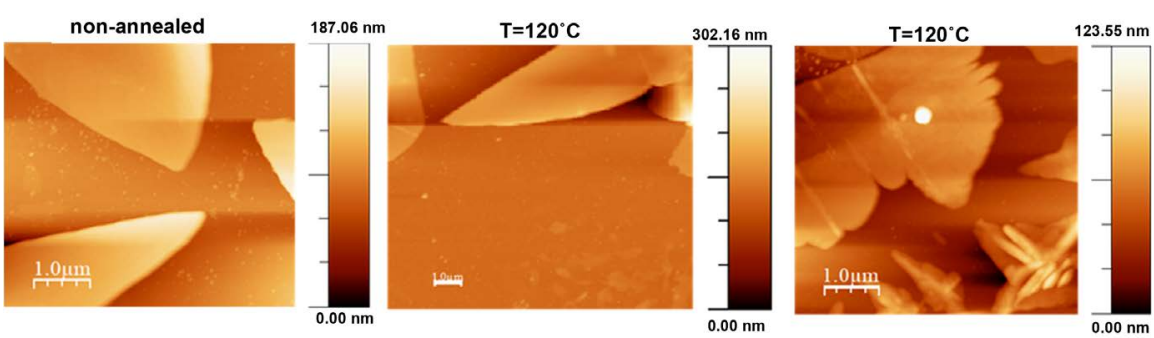

(a)
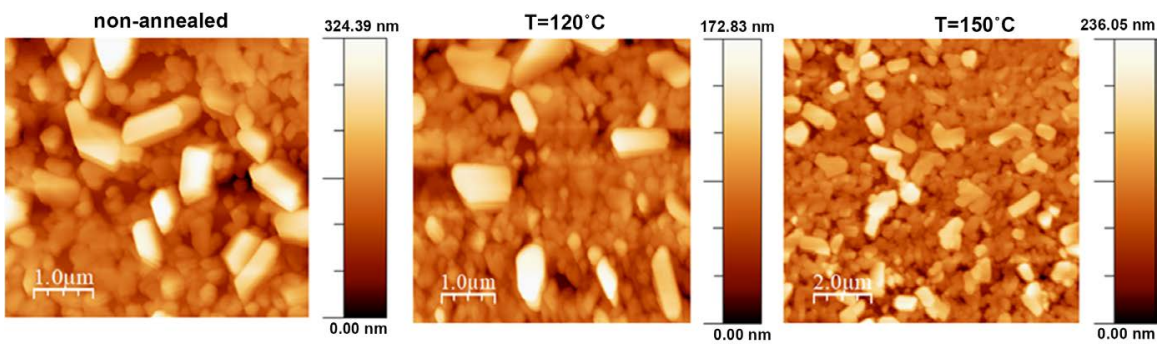

(b)
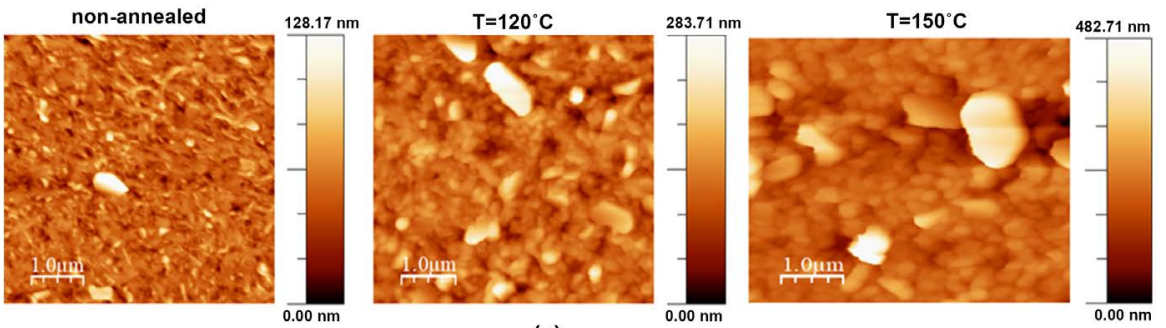

(c)

Figure 3. AFM images of TIPS-pentacene film cast: (a) from toluene, (b) from Chlorobenzene (CB) and (c) from Tetrahydrofuran (THF).

From the AFM images of Figures 3(a)-(c), it is clearly observed the effect of postfabrication thermal treatment. The grain size in toluene's case increases with temperature: $72 \mathrm{~nm}$ for non-annealed $70 \mathrm{~nm}$ for heated at $120^{\circ} \mathrm{C}$ and $151 \mathrm{~nm}$ for annealed at $150^{\circ} \mathrm{C}$. The grain size of TIPS-pentacene in CB is $191 \mathrm{~nm}, 61 \mathrm{~nm}$ and $96 \mathrm{~nm}$ for as-prepared, $120^{\circ} \mathrm{C}$ and $150^{\circ} \mathrm{C}$. And for THF, the grain sizes are $29.9 \mathrm{~nm}, 49 \mathrm{~nm}$, and $82 \mathrm{~nm}$ respectively for non-annealed, $120^{\circ} \mathrm{C}$ and $150^{\circ} \mathrm{C}$. The non-annealed film exhibits many small projections and has a grain size of less than $30 \mathrm{~nm}$ (Figure 3(c): non-annealed). The largest of crystal grain suggesting that during thermal annealing, some adjacent TIPS-pentacene grains in the non-annealed or annealed at $120^{\circ} \mathrm{C}$ film join together via a recrystallization process. Several works show postfabrication thermal annealing influence in grain size that could improve electrical performance [21] [25] [41] [42]. The roughness (RMS) of spin-coated film from toluene decreased when increasing postfabrication annealing temperature. Figure 4 shows the output and transfer characteristics of a Bottom-Gate/Bottom-Contact (BG/BC) TIPS-pentacene FETs cast respectively from toluene, chlorobenzene and tetrahydrofuran as solvent. The organic transistors operate in the accumulation mode since the gate electrode is biased negatively with respect to the grounded source electrode. Drain current $\left(I_{D}\right)$ is almost linear with drain voltage at low $V_{D}$, whereas it tends to 


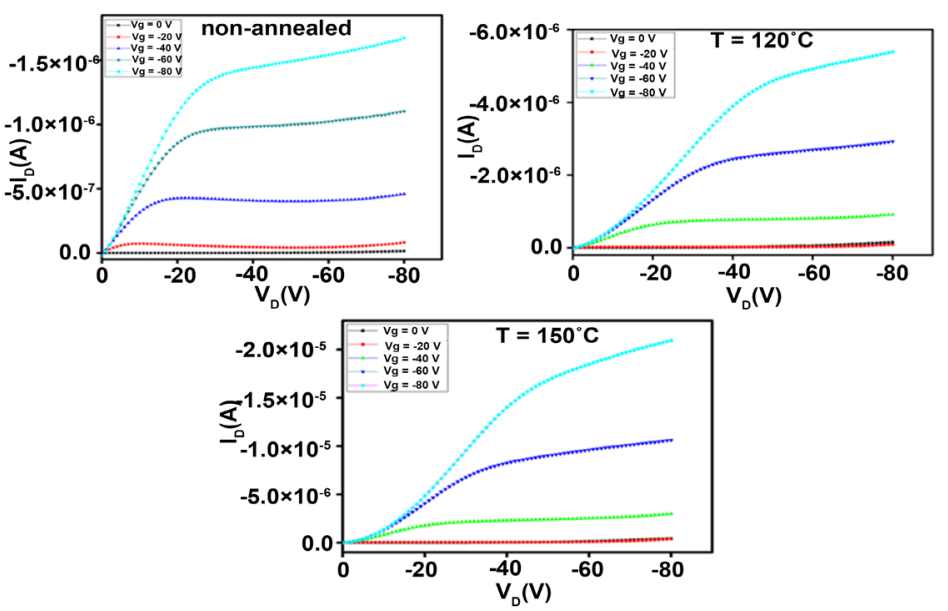

(a)
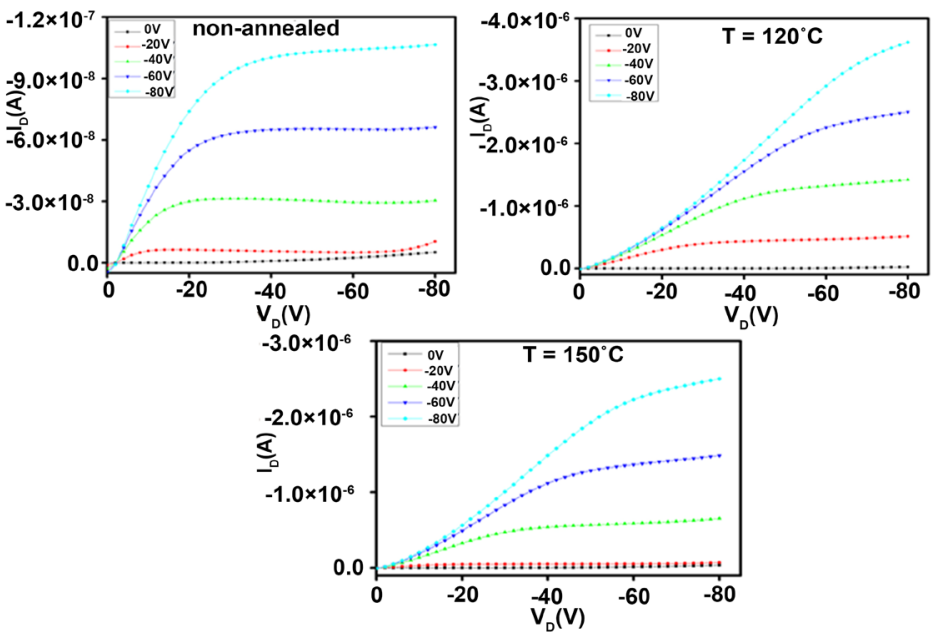

(b)

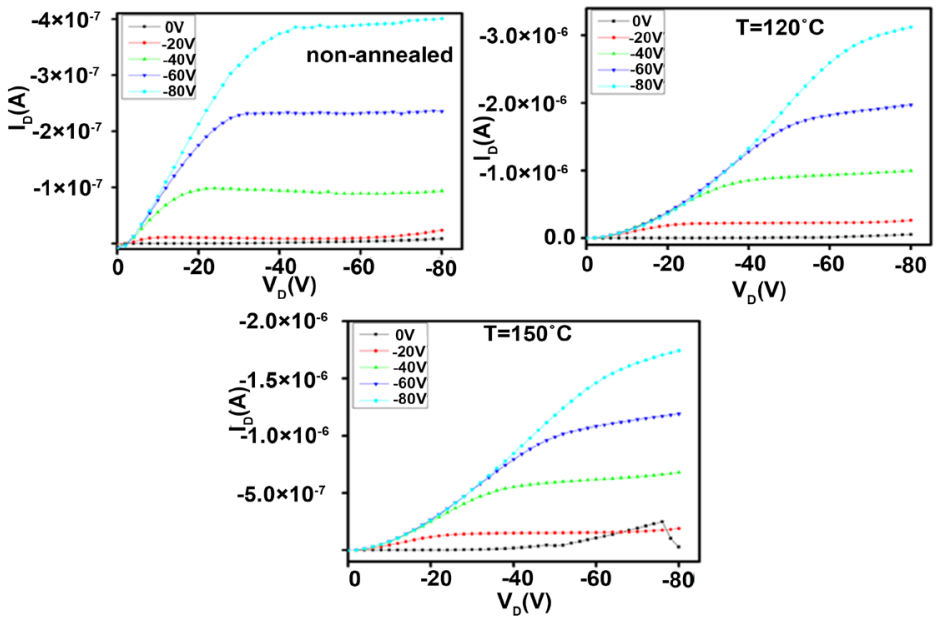

(c)

Figure 4. Output characteristics of TIPS-pentacene FETs: (a) Non-annealed, $120^{\circ} \mathrm{C}$ and $150^{\circ} \mathrm{C}$ for toluene used as solvent; (b) For non-annealed, $120^{\circ} \mathrm{C}$ and $150^{\circ} \mathrm{C}$ respectively for Chlorobenzene used as solvent; (c) Using tetrahydrofuran as solvent respectively for no-annealed, $120^{\circ} \mathrm{C}$ and $150^{\circ} \mathrm{C}$. 
saturate at higher drain voltage due to the pinch off of the accumulation layer. For all electrical output characteristics (Figure 4) we clearly observed a linear and saturation regime confirming a field effect behaviour despite the contact resistance effect appears at the origin when temperature increases.

In the case of toluene as solvent, the field effect mobility was $1.2 \times 10^{-3}$ $\mathrm{cm}^{2} \cdot \mathrm{V}^{-1} \cdot \mathrm{s}^{-1}, \quad 1.5 \times 10^{-3} \mathrm{~cm}^{2} \cdot \mathrm{V}^{-1} \cdot \mathrm{s}^{-1}$ and $4.5 \times 10^{-3} \mathrm{~cm}^{2} \cdot \mathrm{V}^{-1} \cdot \mathrm{s}^{-1}$ respectively for no-annealed and for thermal annealed at $120^{\circ} \mathrm{C}$ and $150^{\circ} \mathrm{C}$. The saturation mobilities were $2.1 \times 10^{-5} \quad \mathrm{~cm}^{2} \cdot \mathrm{V}^{-1} \cdot \mathrm{s}^{-1}, \quad 7.1 \times 10^{-3} \quad \mathrm{~cm}^{2} \cdot \mathrm{V}^{-1} \cdot \mathrm{s}^{-1}, \quad 1.34 \times 10^{-4}$ $\mathrm{cm}^{2} \cdot \mathrm{V}^{-1} \cdot \mathrm{s}^{-1}$ and $1.41 \times 10^{-4} \quad \mathrm{~cm}^{2} \cdot \mathrm{V}^{-1} \cdot \mathrm{s}^{-1}, \quad 1.43 \times 10^{-3} \quad \mathrm{~cm}^{2} \cdot \mathrm{V}^{-1} \cdot \mathrm{s}^{-1}, \quad 5.13 \times 10^{-4}$ $\mathrm{cm}^{2} \cdot \mathrm{V}^{-1} \cdot \mathrm{s}^{-1}$ respectively for $\mathrm{CB}$ and THF at non-annealed, $120^{\circ} \mathrm{C}$ and $150^{\circ} \mathrm{C}$. The slight increase of the mobility could be explained by thermal organisation of film morphology after annealing. The field-effect mobility increases with decreasing the surface roughness (RMS $16.65 \mathrm{~nm}$ at $150^{\circ} \mathrm{C}$ for toluene, $27.51 \mathrm{~nm}$ at $120^{\circ} \mathrm{C}$ for $\mathrm{CB}$ and $37.08 \mathrm{~nm}$ at $120^{\circ} \mathrm{C}$ for THF) (Table 2).

From this table one could observe the evolution of the surface roughness with grain size depending on the annealing temperature. From Figure 4(b) and Figure 4 (c), one could observe the instability of device performance with decreasing of drain current when the annealing temperature is above $120^{\circ} \mathrm{C}$. As it is shown by Kim et al. [30] this instability is induced by solvent impurities. The presence of impurities or additional ions at the semiconductor/dielectric interface might induce positive threshold voltage shift observed in devices with $\mathrm{CB}$ and THF. This phenomenon is commonly observed in solution processed $\mathrm{p}$-type OFETs in which absorbed water molecules could influence the charge transport. The TIPS-pentacene devices using toluene present negative threshold voltage. At high temperature-temperature above the boiling point of those solvents-the polar atom of the solvent could be ionised and affect the interface of conduction channel. The drain current decrease could also be explained by the contact resistance effect appearing at the origin of the characteristic. The solvent could also influence the field-effect mobility. Kim et al. [32] showed that the field-effect mobility increases when the solvent polarity is increased. Many studies showed

Table 2. Electrical parameters of OFETs and film morphological properties.

\begin{tabular}{ccccccc}
\hline Solvents & Temperature & $\mu\left(10^{-3} \mathrm{~cm}^{2} \cdot \mathrm{V}^{-1} \cdot \mathrm{s}^{-1}\right)$ & $\mathrm{V}_{\mathrm{Th}}(\mathrm{V})$ & $\mathrm{I}_{\text {on }} / \mathrm{I}_{\text {off }}$ & $\begin{array}{c}\text { RMS } \\
(\mathrm{nm})\end{array}$ & $\begin{array}{c}\text { Grain size } \\
(\mathrm{nm})\end{array}$ \\
\hline \multirow{2}{*}{ Toluene } & Non-annealed & 1.2 & -2.5 & $8 \cdot 10^{3}$ & 20.41 & 72 \\
& $120^{\circ} \mathrm{C}$ & 1.5 & -6.2 & $10^{3}$ & 22.4 & 70 \\
& $150^{\circ} \mathrm{C}$ & 4.5 & -4.3 & $7 \cdot 10^{2}$ & 16.65 & 151 \\
$\mathrm{CB}$ & Non-annealed & 0.021 & 6.8 & $10^{4}$ & 57.79 & 191 \\
& $120^{\circ} \mathrm{C}$ & 7.1 & -2.4 & $10^{3}$ & 27.51 & 61 \\
& $150^{\circ} \mathrm{C}$ & 0.13 & -2.5 & 18.7 & 34.01 & 96 \\
$\mathrm{THF}$ & $\mathrm{Non}-$ annealed & 0.14 & 6.1 & $2.2 \cdot 10^{3}$ & 13.67 & 29.9 \\
& $120^{\circ} \mathrm{C}$ & 1.4 & 1.1 & $1.2 \cdot 10^{3}$ & 37.08 & 49 \\
& $150^{\circ} \mathrm{C}$ & 0.51 & 2.2 & 50 & 63.07 & 82 \\
\hline
\end{tabular}


how annealing could affect the morphology of film by creating cracks when solvent is removed consequently the charge carries transport is affected [10] [43]. With a boiling point of $66^{\circ} \mathrm{C}$ for THF, film obtained from THF used as solvent is rough and disorganized with small grain size. This behavior could be attributed to a rapid solidification of the deposited film. In contrast to high boiling point solvent, the material crystallizes better when increasing temperature with well-ordered film. Toluene and chlorobenzene have respectively $111^{\circ} \mathrm{C}$ and $132^{\circ} \mathrm{C}$ as boiling point. So the film has sufficient time to be well organized. This could explain the highest value $7.1 \times 10^{-3} \mathrm{~cm}^{2} \cdot \mathrm{V}^{-1} \cdot \mathrm{s}^{-1}$ obtained for OFETs fabricated from chlorobenzene annealed at $120^{\circ} \mathrm{C}$ and $4.5 \times 10^{-3} \mathrm{~cm}^{2} \cdot \mathrm{V}^{-1} \cdot \mathrm{s}^{-1}$ at $150^{\circ} \mathrm{C}$ for the toluene using as solvents.

\section{Conclusion}

In summary, we report solvent and temperature effects on performance of TIPS-pentacene usingtoluene, chlorobenzene and tetrahydrofuran with different boiling points. The optical band gap of TIPS-pentacene is not affected by the annealing temperature and solvent. In contrast the electrical parameters are highly affected by the solvent and annealing temperature. We found that increasing annealing temperature led to increase the field effect mobility. This observation suggests a crystalline structure organisation in TIPS-pentacene semiconductor depending on temperature and used solvent. The processing conditions being highly crucial for device performance, it is well desired in these conditions to take into account solvent and temperature annealing in solution-processed organic transistor. This study confirms and points out the role of slow evaporation rate in solvent and annealing temperature which are of outmost prominence to improve molecular organisation and promote charge transport in organic semiconductor. Transistor devices using Toluene and chlorobenzene as solvents exhibited better performances.

\section{Conflicts of Interest}

The authors declare no conflicts of interest regarding the publication of this paper.

\section{References}

[1] Feng, L., Tang, W., Zhao, J., Cui, Q., Jiang, C. and Guo, X. (2014) All-Solution-Processed Low-Voltage Organic Thin-Film Transistor Inverter on Plastic Substrate. IEEE Transactions on Electron Devices, 61, 1175-1180. https://doi.org/10.1109/TED.2014.2303992

[2] Raghuwanshi, V., Bharti, D. and Tiwari, S.P. (2016) Flexible Organic Field-Effect Transistors with TIPS-Pentacene Crystals Exhibiting High Electrical Stability upon Bending. Organic Electronics, 31, 177-182. https://doi.org/10.1016/j.orgel.2016.01.030

[3] Shin, S.-I., Kwon, J.-H., Kang, H. and Ju, B.-K. (2008) Solution-Processed 6, 13-bis(triisopropylsilylethynyl) (TIPS) Pentacene Thin-Film Transistors with a Polymer Dielectric on a Flexible Substrate. Semiconductor Science and Technology, 
23, 0850091-0850094. https://doi.org/10.1088/0268-1242/23/8/085009

[4] McCulloch, I., Heeney, M., Bailey, C., Genevicius, K., MacDonald, I., Shkunov, M., Sparrowe, D., Tierney, S., Wagner, R., Zhang, W., Chabinyc, M., Kline, R.J., McGehee, M.D. and Toney, M. (2006) Liquid-Crystalline Semiconducting Polymers with High Charge-Carrier Mobility. Nature Materials, 5, 328-333.

https://doi.org/10.1038/nmat1612

[5] Chen, J., Martin, D.C. and Anthony, J.E. (2007) Morphology and Molecular Orientation of Thin-Film bis(triisopropylsilylethynyl) Pentacene. Journal of Materials Research, 22, 1701-1709. https://doi.org/10.1557/JMR.2007.0220

[6] Park, S.K., Mourey, D.A., Han, J.-I., Anthony, J.E. and Jackson, T.N. (2009) Environmental and Operational Stability of Solution-Processed 6,13-bis(triisopropylsilylethynyl)pentacene Thin Film Transistors. Organic Electronics, 10, 486-490. https://doi.org/10.1016/j.orgel.2009.02.007

[7] Park, S.K., Jackson, T.N., Anthony, J.E. and Mourey, D.A. (2007) High Mobility Solution Processed 6,13-bis(triisopropyl-silylethynyl)pentacene Organic Thin Film Transistors. Applied Physics Letters, 91, 0635141-0635143. https://doi.org/10.1063/1.2768934

[8] Giri, G., Miller, E. and Bao, Z. (2014) Selective Solution Shearing Deposition of High Performance TIPS-Pentacene Polymorphs through Chemical Patterning. Journal of Materials Research, 29, 2615-2624. https://doi.org/10.1557/jmr.2014.305

[9] Park, M., Min, Y., Lee, Y.-J. and Jeong, U. (2014) Growth of Long Triisopropylsilylethynyl Pentacene (TIPS-PEN) Nanofibrils in a Polymer Thin Film during Spin-Coating. Macromolecular Rapid Communications, 35, 655-660. https://doi.org/10.1002/marc.201300837

[10] Keum, C.-M., Kwon, J.-H., Lee, S.-D. and Bae, J.-H. (2013) Control of the Molecular Order and Cracks of the 6,13-bis(triisopropylsilylethynyl)-pentacene on a Polymeric Insulator by Anisotropic Solvent Drying. Solid-State Electronics, 89, 189-193. https://doi.org/10.1016/j.sse.2013.08.010

[11] Sakamoto, K., Bulgarevich, K. and Miki, K. (2014) Small Device-to-Device Variation of 6,13-bis(triisopropylsilylethynyl)pentacene Field-Effect Transistor Arrays Fabricated by a Flow-Coating Method. Japanese Journal of Applied Physics, 53, 02BE011-02BE016. https://doi.org/10.7567/JJAP.53.02BE01

[12] Hwang, D.K., Fuentes-Hernandez, C., Berrigan, J.D., Fang, Y., Kim, J., Potscavage, W.J., Cheun, H., Sandhage, K.H. and Kippelen, B. (2012) Solvent and Polymer Matrix Effects on TIPS-Pentacene/Polymer Blend Organic Field-Effect Transistors. Journal of Materials Chemistry, 22, 5531-5537. https://doi.org/10.1039/c2jm16487f

[13] Wang, K., Chen, R., Zhuang, F., Chen, C., Su, S. and Xiang, Y. (2015) Study of Triisopropylsilyl Pentacene Thin Film and Its Interfacial Properties for Device Applications. Thin Solid Films, 584, 359-362. https://doi.org/10.1016/j.tsf.2015.01.054

[14] Sim, K., Choi, H., Cho, S. and Yoon, S.C. (2009) Soluble Pentacene Thin-Film Transistor Using a High Solvent and Heat Resistive Polymeric Dielectric with Low-Temperature Processability and Its Long-Term Stability. Organic Electronics, 10, 506-510. https://doi.org/10.1016/j.orgel.2008.12.016

[15] Cho, S.Y., Ko, J.M., Lim, J., Lee, J.Y. and Lee, C. (2013) Inkjet-Printed Organic Thin Film Transistors Based on TIPS Pentacene with Insulating Polymers. Journal of Materials Chemistry C, 1, 914-923. https://doi.org/10.1039/C2TC00360K

[16] Akkerman, H.B., Li, H. and Bao, Z. (2012) TIPS-Pentacene Crystalline Thin Film Growth. Organic Electronics, 13, 2056-2062.

https://doi.org/10.1016/j.orgel.2012.06.019 
[17] Fichou, D., Demanze, F., Horowitz, G., Hajlaoui, R., Constant, M. and Gamier, F. (1997) Structural, Spectroscopic and Device Characteristics of Octithiophene. Synthetic Metals, 85, 1309-1312. https://doi.org/10.1016/S0379-6779(97)80253-6

[18] Kim, M.J., Heo, H.W., Suh, Y.K. and Song, C.K. (2011) Morphology Control of TIPS-Pentacene Grains with Inert Gas Injection and Effects on the Performance of OTFTs. Organic Electronics, 12, 1170-1176. https://doi.org/10.1016/j.orgel.2011.03.034

[19] Kang, S.-J., Song, S., Liu, C., Kim, D.-Y. and Noh, Y.-Y. (2014) Evolution in Crystal Structure and Electrical Performance of Thiophene-Based Polymer Field Effect Transistors: A Remarkable Difference between Thermal and Solvent Vapor Annealing. Organic Electronics, 15, 1972-1982. https://doi.org/10.1016/j.orgel.2014.05.026

[20] Alberga, P.A., Ciofini, I., Mangiatordi, G.F., Lattanzi, G. and Adamo, C. (2015) Morphological and Charge Transport Properties of Amorphous and Crystalline P3HT and PBTTT: Insights from Theory. Physical Chemistry Chemical Physics, 17, 18742-18750. https://doi.org/10.1039/C5CP02769A

[21] Dinelli, F., Murgia, M., Biscarini, F. and De Leeuw, D.M. (2004) Thermal Annealing Effects on Morphology and Electrical Response in Ultrathin Film Organic Transistors. Synthetic Metals, 146, 373-376. https://doi.org/10.1016/j.synthmet.2004.08.016

[22] Tsao, H.N. and Müllen, K. (2010) Improving Polymer Transistor Performance via Morphology Control. Chemical Society Reviews, 39, 2372-2386. https://doi.org/10.1039/b918151m

[23] Garnier, F., Deloffre, F., Horowitz, G. and Hajlaoui, R. (1993) Structure Effect on Transport of Charge Carriers in Conjugated Oligomers. Synthetic Metals, 57, 4747-4754. https://doi.org/10.1016/0379-6779(93)90812-B

[24] Vakhshouri, K. and Gomez, E.D. (2012) Effect of Crystallization Kinetics on Microstructure and Charge Transport of Polythiophenes. Macromolecular Rapid Communications, 33, 2133-2137. https://doi.org/10.1002/marc.201200531

[25] Ahn, T., Jung, H., Suk, H.J. and Yi, M.H. (2009) Effect of Postfabrication Thermal Annealing on the Electrical Performance of Pentacene Organic Thin-Film Transistors. Synthetic Metals, 159, 1277-1280. https://doi.org/10.1016/j.synthmet.2009.02.023

[26] Lassnig, R., Hollerer, M., Striedinger, B., Fian, A., Stadlober, B. and Winkler, A. (2015) Optimizing Pentacene Thin-Film Transistor Performance: Temperature and Surface Condition Induced Layer Growth Modification. Organic Electronics, 26, 420-428. https://doi.org/10.1016/j.orgel.2015.08.016

[27] Pingel, P., Zen, A., Abellón, R.D., Grozema, F.C., Siebbeles, L.D. and Neher, D. (2010) Temperature-Resolved Local and Macroscopic Charge Carrier Transport in Thin P3HT Layers. Advanced Functional Materials, 20, 2286-2295. https://doi.org/10.1002/adfm.200902273

[28] Qadir, K.W., Ahmad, Z. and Sulaiman, K. (2015) Thermal Annealing Effect on the Optical, Electrical and Morphological Properties of the PBTTT-C12:PC71BM Blend Films. Journal of Solar Energy Engineering, 137, Article ID: 034503. https://doi.org/10.1115/1.4029230

[29] Cho, S., Lee, K., Yuen, J., Wang, G., Moses, D., Heeger, A.J., Surin, M. and Lazzaroni, R. (2006) Thermal Annealing-Induced Enhancement of the Field-Effect Mobility of Regioregular Poly(3-hexylthiophene) Films. Journal of Applied Physics, 100, Article ID: 114503. https://doi.org/10.1063/1.2400796

[30] Kim, C.S., Lee, S., Gomez, E.D., Anthony, J.E. and Loo, Y.-L. (2008) Sol- 
vent-Dependent Electrical Characteristics and Stability of Organic Thin-Film Transistors with Drop Cast Bis(triisopropylsilylethynyl) Pentacene. Applied Physics Letters, 93, Article ID: 103302. https://doi.org/10.1063/1.2979691

[31] Chae, G.J., Jeong, S.-H., Baek, J.H., Walker, B., Song, C.K. and Seo, J.H. (2013) Improved Performance in TIPS-Pentacene Field Effect Transistors Using Solvent Additives. Journal of Materials Chemistry C, 1, 4216-4221. https://doi.org/10.1039/c3tc30506f

[32] Kim, H., Bae, J.-H., Horowitz, G., Kim, W.Y. and Choi, Y. (2013) Effects of the Solvent Polarity of a Polymeric Insulator on Field-Effect Mobility in an Organic Thin-Film Transistor. Solid-State Electronics, 81, 140-143. https://doi.org/10.1016/j.sse.2012.12.014

[33] Kim, Y.-H., Lee, Y.U., Han, J.-I., Han, S.-M. and Han, M.-K. (2007) Influence of Solvent on the Film Morphology, Crystallinity and Electrical Characteristics of Triisopropylsilyl Pentacene OTFTs. Journal of the Electrochemical Society, 154, H995-H998. https://doi.org/10.1149/1.2783765

[34] Gaikwad, A.M., Khan, Y., Ostfeld, A.E., Pandya, S., Abraham, S. and Arias, A.C. (2016) Identifying Orthogonal Solvents for Solution Processed Organic Transistors. Organic Electronics, 30, 18-29. https://doi.org/10.1016/j.orgel.2015.12.008

[35] Wang, S., Tang, J.-C., Zhao, L.-H., Png, R.-Q., Wong, L.-Y., Chia, P.-J., Chan, H.S.O., Ho, P.K.-H. and Chua, L.-L. (2008) Solvent Effects and Multiple Aggregate States in High-Mobility Organic Field-Effect Transistors Based on Poly(bithiophene-alt-thienothiophene). Applied Physics Letters, 93, 1621031-1621033. https://doi.org/10.1063/1.3001574

[36] Abu-Sen, L., Morrison, J.J., Horn, A.B. and Yeates, S.G. (2014) Concentration- and Solvent-Dependent Photochemical Instability of 6,13-Bis(triisopropysilylethynyl) Pentacene. Advanced Optical Materials, 2, 636-640. https://doi.org/10.1002/adom.201400003

[37] Gunduz, B. and Yakuphanoglu, F. (2012) Effects of UV and White Light Illuminations on Photosensing Properties of the 6,13-bis(triisopropylsilylethynyl)pentacene Thin Film Transistor. Sensors and Actuators A: Physical, 178, 141-153. https://doi.org/10.1016/j.sna.2012.02.032

[38] Platt, A.D., Day, J., Subramanian, S., Anthony, J.E. and Ostroverkhova, O. (2009) Optical, Fluorescent, and (Photo)conductive Properties of High-Performance Functionalized Pentacene and Anthradithiophene Derivatives. The Journal of Physical Chemistry C, 113, 14006-14014. https://doi.org/10.1021/jp904021p

[39] Davis, R.J., Lloyd, M.T., Ferreira, S.R., Bruzek, M.J., Watkins, S.E., Lindell, L., Sehati, P., Fahlman, M., Anthony, J.E. and Hsu, J.W.P. (2011) Determination of Energy Level Alignment at Interfaces of Hybrid and Organic Solar Cells under Ambient Environment. Journal of Materials Chemistry, 21, 1721-1729. https://doi.org/10.1039/C0JM02349C

[40] Saeed, Y., Zhao, K., Singh, N., Li, R., Anthony, J.E., Amassian, A. and Schwingenschlögl, U. (2013) Influence of Substitution on the Optical Properties of Functionalized Pentacene Monomers and Crystals: Experiment and Theory. Chemical Physics Letters, 585, 95-100. https://doi.org/10.1016/j.cplett.2013.08.023

[41] Liu, S.-W., Huang, J.-C., Lee, C.-C., Lee, C.-T. and Wang, J.-K. (2007) Improving Stability of Pentacene Field-Effect Transistors with Post-Annealing. Symposium F-Interfaces in Organic and Molecular Electronics III, 1029.

[42] Murtaza, G., Ahmad, I., Chen, H. and Wu, J. (2014) Study of 6,13-bis(tri-isopropylsilylethynyl) Pentacene (TIPS-Pentacene Crystal) Based Organic Field Effect 
Transistors (OFETs). Synthetic Metals, 194, 146-152.

https://doi.org/10.1016/j.synthmet.2014.04.034

[43] Chen, J., Tee, C.K., Yang, J., Shaw, C., Shtein, M., Anthony, J. and Martin, D.C. (2006) Thermal and Mechanical Cracking in Bis(triisopropylsilylethnyl) Pentacene Thin Films. Journal of Polymer Science Part B: Polymer Physics, 44, 3631-3641. 